\title{
Knowledge level of dairy farmers regarding clean milk production practices at field level in western U.P.
}

YOGENDRA KUMAR AND CHETAN PRAKASH

Author for Corresponding -

\section{YOGENDRA KUMAR}

Department of Animal

Husbandry and Dairying, Kisan

(P.G.) College, Simbhaoli, HAPUR

(U.P.) INDIA

Email: dryogendrakumarkd@

gmail.com

See end of the article for

Coopted authors'

\begin{abstract}
The milk quality is determined by aspects of composition and hygiene of milk, where breeding, feeding, management of healthcare, fodder production, and many such facts mainly influence the compositional quality of milk. Dairy farmer is the key client in this process, who decides the quality of milk from milk production to milk supply chain. This study was conducted to know the level of knowledge of dairy farmers regarding clean milk production practices. Uttar Pradesh state was selected purposively for this study, where 120 dairy farmers (60 CMP and $60 \mathrm{~N}-\mathrm{CMP}$ ) from the milk shed area of four districts milk union were selected. The results of the study revealed that 71.67 and 61.67 per cent of the dairy farmers had medium level of knowledge in various aspects of CMP and N-CMP followed by 10 and 25 per cent had low level of knowledge while, 18.33 and 13.33 per cent of them having high level of knowledge, respectively. They had highest knowledge in milking [Knowledge index $(\mathrm{KI})=75.41$ and 68.45], followed by healthy herd management $(\mathrm{KI}=66.84$ and 61.54$)$. However, they had poor knowledge in "cooling of milk ( $\mathrm{KI}=56.66$ and 51.12) and "cleaning of utensils ( $\mathrm{KI}=58.22$ and 54.58) in CMP and N-CMP, respectively.
\end{abstract}

KEY WORDS...... Knowledge index, CMP, Practices, N-CMP, Dairy farmer, Milk union

HOW TO CITE THIS ARTICLE - Kumar, Yogendra and Prakash, Chetan (2017). Knowledge level of dairy farmers regarding clean milk production practices at field level in western U.P. Asian J. Animal Sci., 12(1): 7-14. DOI : 10.15740/HAS/TAJAS/12.1/7-14.

ARTICLE CHRONICLE - Received : 07.01.2017; Revised : 02.05.2017; Accepted : 16.05.2017 